\title{
Juvenile Chronic Arthritis: T Cell Reactivity to Human HSP60 in Patients with a Favorable Course of Arthritis
}

\author{
Elisabeth R. de Graeff-Meeder, ${ }^{*}$ Willem van Eden," Ger T. Rijkers, ${ }^{*}$ Berent J. Prakken, ${ }^{*}$ Wietse Kuis," \\ Marleen M. Voorhorst-Ogink, ${ }^{\star}$ Ruurd van der Zee," Henk-Jan Schuurman, ${ }^{\S}$ Paul J. M. Helders, ${ }^{\ddagger}$ and Ben J. M. Zegers` \\ Department of *Immunology and the ${ }^{\ddagger}$ Department of Pediatric Physiotherapy, University Hospital for Children and Youth "Het \\ Wilhelmina Kinderziekenhuis"'; ${ }^{\S}$ Division of Histochemistry and Electron Microscopy, Departments of Pathology and Internal Medicine, \\ University Hospital; and the "Institute of Infectious Diseases and Immunology, Faculty of Veterinary Medicine, University of Utrecht, \\ Utrecht, The Netherlands
}

\begin{abstract}
Synovial fluid and peripheral blood mononuclear cell proliferative responses to the $60-\mathrm{kD}$ human heat shock protein (HSP60) were studied in 23 patients with juvenile chronic arthritis (JCA) and 7 non-JCA control patients. All patients showed active arthritis at the time of study. The patients were divided into two groups according to the presence (group A) or absence (group B) of $\mathrm{T}$ lymphocyte reactivity to human HSP60. We show that reactivity to human HSP60 is primarily, though not exclusively, occurring in patients with a remitting course of disease, i.e., the subgroup of HLAB27 negative JCA patients with an oligoarticular onset. Immunohistochemical analysis of HSP expression in synovial membranes showed a significantly higher intensity of staining in JCA patients than in non-JCA controls. The results suggest that, in accordance with the earlier observation made in experimental models, $T$ lymphocyte reactivity to human HSP60 in this subgroup of JCA patients may be part of $T$ cell regulatory mechanisms that control the development of arthritis. (J. Clin. Invest. 1995. 95:934-940.) Key words: juvenile chronic arthritis - heat shock proteins - T lymphocytes
\end{abstract}

\section{Introduction}

Juvenile chronic arthritis (JCA) ${ }^{1}$ encompasses a heterogeneous group of rheumatic diseases. Three subgroups of JCA (oligoarticular, polyarticular, and systemic onset) are recognized. They can be distinguished on the basis of clinical features presenting during the first 3 mo of the disease (1). The etiology of JCA is still unknown and the pathogenetic mechanisms remain unclear.

Recent research in the field of rheumatology has focused on the key position of $\mathrm{T}$ lymphocytes in the immunopathologic

Address correspondence to E. R. de Graeff-Meeder, University Hospital for Children and Youth, P.O. Box 18009, 3501 CA Utrecht, The Netherlands. Phone: 30-320911; FAX: 30-320712/334825. 1994.

Received for publication 7 July 1994 and in revised form 25 October

1. Abbreviations used in this paper: AA, adjuvant arthritis; ANA, antinuclear antibodies; HSP60, heat shock protein; JCA, juvenile chronic arthritis; MNC, mononuclear cells; MT, Mycobacterium tuberculosis.

J. Clin. Invest.

(C) The American Society for Clinical Investigation, Inc. 0021-9738/95/03/0934/07 \$2.00

Volume 95, March 1995, 934-940 mechanisms leading to disease. Experimental models of arthritis, such as adjuvant arthritis (AA), have been instrumental in this respect (2). The mycobacterial $65-\mathrm{kD}$ antigen (member of the HSP60 heat shock protein family) was defined originally as a crucial antigen associated with disease development (3). This has initiated an analysis of the role of bacterial HSP60 or its endogenous mammalian homologue HSP60 in various forms of arthritis, both in animals and in humans. In the experimental model of arthritis in animals it has become clear that immunity to mycobacterial HSP60 develops irrespective of how the arthritis was induced. This was seen not only in AA in rats but also in pristane-induced arthritis in mice (4) and streptococcal cell wall induced arthritis in rats (5). Subsequently, it has been shown in these models and in collagen-induced arthritis (6) that preimmunization with HSP60 itself or transfer of HSP60primed $\mathrm{T}$ lymphocytes induced resistance to arthritis. These experimental data have been interpreted as indicating that $T$ lymphocyte reactivity against mycobacterial HSP60 is part of regulatory mechanisms that control the development of arthritis (2).

Recently, we showed that the $60-\mathrm{kD}$ human heat shock protein (human HSP60) can be a target antigen for synovial fluid and peripheral blood mononuclear cells (PBMC) in JCA patients (7). This finding prompted us to evaluate in more detail the significance of in vitro reactivity to human HSP60 of mononuclear cells (MNC) from patients with JCA. To this end, a number of JCA patients with active arthritis were grouped according to the presence or absence of anti-human HSP60 reactivity, either of synovial fluid MNC or of PBMC. Apart from clinical analysis, $\mathrm{T}$ lymphocyte subsets in peripheral blood and synovial fluid were determined, next to expression of HSP60 in synovial membranes by immunohistochemistry (8). We now show that JCA patients manifesting in vitro anti-human HSP60 reactivity of $\mathrm{T}$ lymphocytes have a relatively mild and usually remitting subtype of JCA, i.e., oligoarticular onset of JCA. This may indicate that $\mathrm{T}$ lymphocyte reactivity to human HSP60 may be part of a protective immunoregulatory response.

\section{Methods}

Patients. The study included 23 patients with JCA (defined by the criteria of the European League against Rheumatism [1]) (Table I, patients 1-23) who ranged in age from 3.3 to $16.3 \mathrm{yr}$. The mean duration of the disease was $1.5 \mathrm{yr}$ (range $0.2-13.3 \mathrm{yr}$ ). In 13 out of 23 patients, both synovial membranes and peripheral blood and/or synovial fluid were available for the study (patients $1-9$ and 15-18). In the remaining 10 patients (Table I, patients $10-14$ and 19-23), only the proliferative response of synovial fluid- or peripheral blood-derived $\mathrm{T}$ lymphocytes to human HSP60 could be assessed. 15 of the 23 patients had an oligoarticular onset of JCA, 6 patients had a polyarticular onset, and 2 patients 
Table I. Clinical Characteristics of Patients with JCA

\begin{tabular}{|c|c|c|c|c|c|c|c|c|c|c|}
\hline & Patient & Sex & $\begin{array}{l}\text { Age at onset } \\
\text { of disease }\end{array}$ & $\begin{array}{l}\text { JCA } \\
\text { type }\end{array}$ & $\mathrm{RF}$ & ANA & HLA-B27 & $\begin{array}{l}\text { Duration } \\
\text { of disease }\end{array}$ & $\begin{array}{l}\text { Duration of } \\
\text { current arthritis }\end{array}$ & $\begin{array}{l}\text { Arthritis activity*/ } \\
\text { functional class }\end{array}$ \\
\hline & & & $y r$ & & & & & $y r$ & $y r$ & \\
\hline \multirow[t]{14}{*}{ Group A } & 1 & $\mathrm{~F}$ & 10.3 & $\mathrm{OA}$ & - & + & - & 0.4 & 0.4 & $2 / 1$ \\
\hline & 2 & $\mathrm{~F}$ & 9.1 & $\mathrm{OA}$ & - & - & - & 0.3 & 0.2 & $2 / 1$ \\
\hline & 3 & $\mathbf{M}$ & 12.1 & $\mathrm{OA}$ & - & - & - & 0.3 & 0.3 & $2 / 2$ \\
\hline & 4 & $\mathbf{M}$ & 11.6 & $\mathrm{OA}$ & - & + & - & 0.3 & 0.3 & $2 / 1$ \\
\hline & 5 & $\mathbf{M}$ & 6.1 & $\mathrm{OA}$ & - & - & - & 2.9 & 0.2 & $1 / 2$ \\
\hline & 6 & $\mathbf{M}$ & 8.0 & PA & - & - & - & 2.0 & 2.0 & $2 / 2$ \\
\hline & 7 & $\mathrm{~F}$ & 1.6 & $\mathrm{OA}$ & - & + & - & 6.5 & 0.2 & $2 / 1$ \\
\hline & 8 & $\mathrm{~F}$ & 10.3 & $\mathrm{OA}$ & - & + & - & 0.2 & 0.2 & $2 / 1$ \\
\hline & 9 & $\mathbf{M}$ & 13.2 & $\mathrm{OA}$ & - & - & - & 1.2 & 1.0 & $2 / 2$ \\
\hline & 10 & $\mathbf{M}$ & 6.5 & SO & - & - & - & 13.0 & 13.0 & $2 / 2$ \\
\hline & 11 & $\mathbf{M}$ & 7.2 & $\mathrm{OA}$ & - & - & - & 1.0 & 0.1 & $1 / 1$ \\
\hline & 12 & $\mathbf{M}$ & 5.2 & $\mathrm{OA}$ & - & + & + & 0.8 & 0.8 & $2 / 2$ \\
\hline & 13 & $\mathrm{~F}$ & 7.1 & PA & + & + & - & 4.0 & 1.0 & $2 / 2$ \\
\hline & 14 & $\mathbf{M}$ & 8.0 & PA & - & - & - & 2.6 & 0.7 & $2 / 1$ \\
\hline \multirow[t]{9}{*}{ Group B } & 15 & $\mathrm{~F}$ & 3.0 & PA & - & + & - & 13.3 & 0.8 & $2 / 2$ \\
\hline & 16 & $\mathrm{~F}$ & 3.1 & $\mathrm{OA}$ & - & - & - & 0.2 & 0.2 & $2 / 2$ \\
\hline & 17 & $\mathbf{M}$ & 3.4 & PA & + & + & - & 2.7 & 1.5 & $2 / 2$ \\
\hline & 18 & $\mathbf{M}$ & 5.7 & SO & - & - & - & 5.8 & 2.2 & $2 / 2$ \\
\hline & 19 & $\mathrm{~F}$ & 15.3 & $\mathrm{OA}$ & - & - & + & 0.8 & 0.8 & $2 / 2$ \\
\hline & 20 & $\mathbf{M}$ & 3.9 & $\mathrm{OA}$ & - & - & - & 1.1 & 0.3 & $2 / 2$ \\
\hline & 21 & $F$ & 11.7 & $\mathrm{OA}$ & - & - & + & 3.0 & 3.0 & $2 / 1$ \\
\hline & 22 & $F$ & 2.8 & PA & - & + & - & 8.1 & 0.2 & $2 / 2$ \\
\hline & 23 & $\mathrm{~F}$ & 12.1 & $\mathrm{OA}$ & - & - & + & 3.1 & 0.5 & $2 / 2$ \\
\hline
\end{tabular}

Groups A and B are defined by a positive and negative T lymphocyte proliferative response to human HSP60, respectively (i.e., stimulation index $>$ or $<3$ ); patients 1-9 and 15-18 are patients from which synovial membranes, peripheral blood, and/or synovial fluid MNC were available; patients 10-14 and 19-23 are patients that were only tested for T lymphocyte response to human HSP60; $O A$, oligoarticular onset; $P A$, polyarticular onset; $S O$, systemic onset; $R F$, rheumatoid factor (determined by Rose-Waaler and latex agglutination). ANA were determined with immunofluorescence on Hep- 2 cells and scored as -, negative tested at serum dilution 1:40, and + , positive. ${ }^{*}$ Scored on basis of formal joint assessment (pain, swelling, and limitation of motion). Functional class score was according to Steinbrocker (9).

had a systemic onset. The latter two patients developed a polyarthritis later on in the study. None of the 23 patients had iridocyclitis at the time of study nor did they develop it later on. Only two patients were positive for rheumatoid factor (determined by Rose-Waaler and latex agglutination). Eight patients had anti-nuclear antibodies (ANA; determined by immunofluorescence on Hep- 2 cells). Four of the patients were HLA-B27 positive. DNA analysis of MHC class II DPB alleles was performed by direct sequencing and DRB by oligotyping. All patients had an active arthritis at the time of study; in 14 patients a single joint was involved, in 2 patients 2 joints (ankle and knee) were involved, and in 7 patients 3 or more joints (knee, ankle, hip, and wrist) were involved. The mean duration of the current arthritis was $0.5 \mathrm{yr}$ (range $0.1-3.0 \mathrm{yr}$ ). Arthritis was scored on formal joint assessments, i.e., swelling and/or tenderness, pain, and limitation of motion where 0 equals no signs of arthritis, 1 equals mild arthritis, 2 equals moderate arthritis, and 3 equals severe arthritis. The mean score of arthritis activity was 1.9 (range 1-2). The functional class was assessed according to Steinbrocker (9). The mean score of the functional class was 1.6 (range 12). Only two of the patients showed bone erosions upon x-ray examination (Table I, patients 10 and 15). Nine patients were studied before treatment was started. 12 patients were under treatment with nonsteroidal antiinflammatory drugs. Two patients were being treated with a combination of nonsteroidal antiinflammatory drugs and sulphasalazine. One of the patients had received prednisone for constitutional symptoms of the systemic form of JCA 2 yr before. None of the other patients had ever received any form of immunosuppressive drugs. Synovial fluids were available from 18 out of 23 patients. Synovial biopsy samples were available from 13 patients (Table I, patients 1-9 and 15-18). These were taken in a stage of active arthritis during arthroscopy of the knee $(n=10)$, hip $(n=2)$, and ankle $(n=1)$. In two patients (patients 8 and 16), the synovial fluid, peripheral blood, and synovial biopsy were taken in an early phase of the disease $(0.2 \mathrm{yr})$. Follow-up showed that the diagnosis of JCA was correct. Peripheral blood samples were taken at the same time.

Non-JCA control patients. Seven non-JCA patients with arthralgia $(n=5)$ or arthritis $(n=2)$ were studied. Their age ranged from 8.1 to $15.1 \mathrm{yr}$. The two cases with arthritis showed a short duration $(<3 \mathrm{mo})$ and osteoid osteoma, respectively, which were reasons to reject the diagnosis of JCA. The mean duration of their symptoms was $1.1 \mathrm{yr}$. Rheumatoid factor was negative in six non-JCA patients. Three nonJCA patients were ANA positive. One out of six non-JCA patients was HLA-B27 positive. Synovial biopsy samples were available for all seven non-JCA patients taken during arthroscopy of the knee $(n=6)$ or the hip $(n=1)$. The synovial fluid of the non-JCA patients did not contain sufficient MNC to perform phenotyping and/or lymphocyte stimulation studies. Peripheral blood samples were taken at the time of the biopsy.

Peripheral blood also was collected from nine healthy children (age range $8.0-15.4 \mathrm{yr}$ ).

Peripheral blood and synovial fluid assays. MNC were isolated from heparinized blood or synovial fluid by Ficoll-Isopaque density gradient centrifugation (Pharmacia AB, Uppsala, Sweden). The cells were suspended at a density of $0.5 \times 10^{6} / \mathrm{ml}$ in RPMI 1640 tissue culture medium, supplemented with $20 \%$ heat-inactivated $\left(30 \mathrm{~min}, 56^{\circ} \mathrm{C}\right)$ human $\mathrm{AB}$ serum, $100 \mu \mathrm{g} / \mathrm{ml}$ penicillin, $100 \mathrm{U} / \mathrm{ml}$ streptomycin, and $200 \mu \mathrm{g} / \mathrm{ml}$ 
glutamine. Cultures of $200 \mu \mathrm{l}$ of suspension $\left(0.1 \times 10^{6}\right.$ cells $)$ containing mitogen or antigen were carried out in quadruplicate in 96-well flatbottomed polystyrene microplates (Nunc, Roskilde, Denmark). Cells were cultured for $6 \mathrm{~d}$ at $37^{\circ} \mathrm{C}$ in $5 \% \mathrm{CO}_{2}$ and $100 \%$ relative humidity. $1 \mu \mathrm{Ci}(37 \mathrm{kBq}$ ) tritiated thymidine (specific activity $75 \mathrm{kBq} / \mathrm{mmol}$; Amersham International, Buckinghamshire, UK) was added to each well during the last $16 \mathrm{~h}$ of culture. Radioactivity incorporated was measured by liquid scintillation counting and expressed as counts per minute. The proliferative response is expressed as stimulation index $=$ the mean counts per minute of cells cultured with mitogen or antigen, divided by the mean counts per minute of cells cultured with medium only. A positive response was defined as a stimulation index of 3 or more.

The antigens used for in vitro cultures were purified protein derivative (10 $\mu \mathrm{g} / \mathrm{ml}$; Statens Seruminstitut, Copenhagen, Denmark); heatkilled Mycobacterium tuberculosis (MT, $10 \mu \mathrm{g} / \mathrm{ml}$ ) (10); AP (the acetone precipitable fraction of MT, $10 \mu \mathrm{g} / \mathrm{ml}$ ) (10); purified GroEL, the Escherichia coli equivalent of HSP60 (a kind gift of D. Young, MRC Tuberculosis and Related Infections Unit, Royal Postgraduate Medical School, Hammersmith Hospital, London); HPLC-purified recombinant mycobacterial HSP60 $(100 \mu \mathrm{g} / \mathrm{ml})$; synthetic peptide $183-188$ of the mycobacterial HSP60, prepared by solid phase synthesis $(100 \mu \mathrm{g} / \mathrm{ml})$ (11); HPLC-purified human HSP60 fractions $(10 \mu \mathrm{g} / \mathrm{ml})$ and HPLC control fractions for human HSP60 $(10 \mu \mathrm{g} / \mathrm{ml})$ as described previously (7); tetanus toxoid (3.5 limit flocculation units $/ \mathrm{ml}$ ); and diphtheria toxoid (3.5 $\mu \mathrm{g} / \mathrm{ml})$. Pokeweed mitogen (10 $\mu \mathrm{g} / \mathrm{ml}$; Calbiochem-Novabiochem Corp., La Jolla, CA) was used as polyclonal activator.

The purity of the human HSP60 preparation was determined by ELISA using a panel of mAbs that react with GroEL, the E. coli HSP60. Optical density (OD) values of wells coated with $1 \mu \mathrm{g} / \mathrm{ml}$ human HSP60 and developed with IT31 (0.107), F67-13 (0.106), or IIH9 (0.109) did not differ significantly from OD values of wells that were developed with $\alpha$ DNAk (an anti-E. coli HSP70 mAb; 0.108 ) or the medium control (0.107). Corresponding OD values for wells coated with $1 \mu \mathrm{g} /$ $\mathrm{ml}$ GroEL were 0.498 (IT31), 1.183 (F67-13), 1.199 (IIH9), 0.111 ( $\alpha$ DNAk), and 0.108 (medium control).

Lymphocyte cell surface markers. PBMC and synovial fluid MNC were washed twice in minimum essential medium supplemented with $1 \%$ BSA and $0.05 \%$ sodium-azide. Subsequently, $0.5-1 \times 10^{6}$ cells were incubated for $30 \mathrm{~min}$ at $4^{\circ} \mathrm{C}$ in $10 \mu \mathrm{l}$ appropriately diluted CD3 (Leu4), TCR $\alpha \beta$ (TCR-1, WT31), TCR $\gamma \delta$ (TCR $\gamma \delta$ ), CD4 (Leu3a), CD8 (Leu2a), CD20 (Leu16), HLA-DR (HLA-DR), or CD29 (4B4) mAbs. All mAbs were from Becton Dickinson (Mountain View, CA), except 4B4 which was from Coulter Corp. (Hialeah, FL). Next, MNC were washed and incubated with FITC-conjugated goat anti-mouse immunoglobulins (Becton Dickinson) for another $30 \mathrm{~min}$ at $4^{\circ} \mathrm{C}$. For two-color immunofluorescence, MNC were incubated in a third step with phycoerythrin-conjugated anti-HLA-DR or CD4. Stained MNC were diluted in sheath fluid and run on a FACStar Plus ${ }^{\circledR}$ flowcytometer (Becton Dickinson). From each sample 10,000 events were stored in list-mode and analyzed using Consort 30 and Lysis I software (Becton Dickinson).

Histology and immunohistochemistry. For histology, part of the synovium biopsy samples was fixed in buffered formalin and embedded in paraffin. 6- $\mu \mathrm{m}$ sections were stained with hematoxylin and eosin. All sections of the JCA patients and the non-JCA control patients were reviewed histologically for the degree of synovitis (scored as absent, mild, moderate, and severe). For immunohistochemistry (see below) another part was snap-frozen and stored at $-70^{\circ} \mathrm{C}$ until analysis. For detection of HSP, five murine monoclonal antibodies were used: F8, raised against a synthetic peptide encompassing amino acid residues 180-188 of mycobacterial HSP60 (8); ML-30, raised against the mycobacterial HSP60 of $M$. leprae (8); N-27, a monoclonal antibody which recognizes both the inducible and constitutive forms of human HSP70 (7); LK1, a murine monoclonal raised against human HSP60, which binds only to mammalian HSP60 (12); and LK2, a murine monoclonal raised against human HSP60, which binds to human HSP60 and bacterial HSP60 as well (12). In addition, a monoclonal anti-HLA-DR antibody was applied (Becton Dickinson). Frozen tissue sections of $8 \mu \mathrm{m}$ were

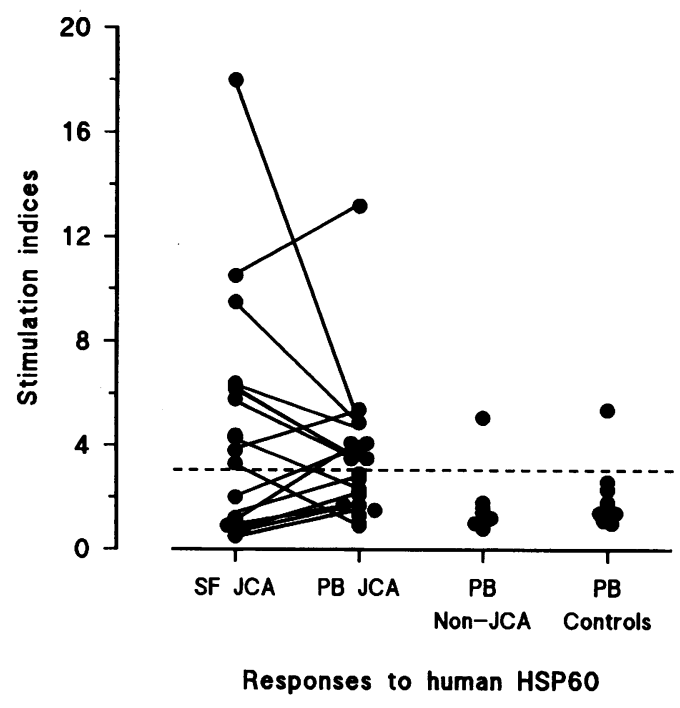

Figure 1. Proliferative response to human HSP60 in JCA patients, nonJCA patients, and healthy control children. $S F$, synovial fluid; $P B$, peripheral blood.

fixed in acetone. A three-step indirect immunoperoxidase method was applied using a first incubation with monoclonal antibody, followed by an incubation with rabbit antibodies to mouse immunoglobulins conjugated to horseradish peroxidase and, subsequently, swine antibodies to rabbit immunoglobulins conjugated to horseradish peroxidase in the third step (both conjugates from DAKOPATTS, Glostrup, Denmark). Staining was performed using 3-3' diaminobenzidine tetrahydrochloride and $\mathrm{H}_{2} \mathrm{O}_{2}$ as substrate. The sections were counterstained with hematoxylin.

All sections were independently scored by two different observers for intensity of staining $(0=$ no staining; $1=$ minor staining; $2=$ moderate staining; $3=$ strong staining). In each section the staining intensities of the synovial lining layer, the endothelium cells and pericytes, the connective tissue and the macrophages were scored separately. The mean values of the scores of both observers of each monoclonal antibody per section were calculated.

Statistical analysis. For comparison of the location of various groups of data a Kruskal-Wallis test was performed because of skewly distributed data. To calculate the correlation between lymphocyte proliferation induced by human HSP60 and the other antigens, a Spearman rank correlation test was performed because of skewly distributed data.

\section{Results}

Patients and definition of groups. T lymphocyte proliferative responses to human HSP60 were tested for synovial fluid or peripheral blood from 23 children suffering from JCA (Fig. 1). To evaluate the significance of this response to human HSP60, the JCA patients were divided into two groups (A and B). A positive response of either synovial fluid or peripheral blood $\mathrm{T}$ lymphocytes (i.e., stimulation index above 3) was observed in 14 patients (Table I, group A, patients 1-14). Nine patients showed a stimulation index below 3 (Table I, group B, patients 15-23). In addition, the proliferative response to human HSP60 was assessed in seven non-JCA control patients as well as in nine healthy children (Fig. 1). One non-JCA patient (a HLAB27-positive boy with a transient arthralgia) and one healthy child also had a positive response. The other non-JCA controls and healthy children showed a negative response. To exclude that the observed in vitro proliferative anti-HSP60 T cell re- 
Table II. Lymphocyte Cell Surface Markers in Synovial Fluid or Peripheral Blood of Patients and Controls*

\begin{tabular}{lcccc}
\hline & \multicolumn{2}{c}{ JCA patients } & $\begin{array}{c}\text { Non-JCA } \\
\text { controls }\end{array}$ \\
\cline { 2 - 3 } & $\mathrm{SF}(n=9)$ & $\mathrm{PB}(n=13$ & & $\mathrm{PB}(n=6)$ \\
\hline $\mathrm{CD} 3$ & 71.7 & 59.8 & 64.1 \\
$\mathrm{TCR} \alpha \beta$ & 58.4 & 54.0 & 56.4 \\
$\mathrm{TCR} \gamma \delta$ & 4.7 & 6.8 & 6.1 \\
$\mathrm{CD} 4$ & 43.1 & 30.3 & 42.8 \\
$\mathrm{CD} 8$ & $32.5^{\ddagger}$ & 25.1 & 23.5 \\
$\mathrm{CD} 4+\mathrm{DR}+$ & $27.1^{\ddagger}$ & 8.0 & 6.5 \\
$\mathrm{CD} 8+\mathrm{DR}+$ & $32.1^{\S}$ & 12.0 & 8.4 \\
$\mathrm{CD} 20$ & 6.3 & 4.5 & 5.4 \\
$\mathrm{CD} 4+\mathrm{CD} 29+$ & $66.9^{\S}$ & 15.6 & 19.9 \\
& & & \\
\hline
\end{tabular}

* Geometric mean values expressed as percentage of lymphocytes. $S F$, synovial fluid; $P B$, peripheral blood. ${ }^{\ddagger} P<0.01 ;{ }^{\S} P<0.05$, significant difference between SF and PB of JCA patients and non-JCA controls.

sponse would have been caused by contaminating trace amounts of GroEL in the purified recombinant human HSP60 preparation, $T$ cells were also cultured with GroEL. In only three out of nine from group A JCA patients that were selected for this purpose, an in vitro proliferative $T$ cell response could be induced with GroEL. However, this required a dose of $10 \mu \mathrm{g} /$ $\mathrm{ml}$ GroEL, and the magnitude of the response, in terms of $\left[{ }^{3} \mathrm{H}\right]$ thymidine incorporation, was only $20 \%$ of that of the antihuman HSP60 response.

The significance of $T$ lymphocyte reactivity to human HSP60 was evaluated by multiparameter analysis of the 13 patients, for which data were available on membrane phenotyping of MNC in synovial fluid and/or peripheral blood; proliferative responses of synovial fluid and peripheral blood $\mathrm{T}$ lymphocytes to HSP60 and other antigens; histology and immunohistochemistry of synovial membranes; and data on the clinical course of the disease. Of these $13 \mathrm{JCA}$-patients available for multiparameter analysis, 9 (patients $1-9$ in Table I) fell in group A and 4 (patients 15-18) fell in group B. All but one of the nine patients of group A had an oligoarticular onset of JCA. The four patients of group B available for multiparameter analysis encompassed two patients with a polyarticular onset of JCA, one patient with a systemic onset, and one patient with an oligoarticular onset of JCA.

Lymphocyte cell surface markers of mononuclear cells in synovial fluid and peripheral blood. The membrane phenotyping of MNC in synovial fluid and peripheral blood of all patients in group A and B and non-JCA controls is shown in Table II. The percentage of $\mathrm{CD}^{+}, \mathrm{CD}^{+} \mathrm{DR}^{+}$, and $\mathrm{CD} 8^{+} \mathrm{DR}^{+} \mathrm{MNC}$ in the synovial fluid of the JCA patients was significantly higher than in the peripheral blood of these patients and the non-JCA controls. Two-color staining for CD4 and CD29 showed that the fraction of $\mathrm{CD} 29^{+}$cells within the $\mathrm{CD} 4^{+}$population, which represent memory $\mathrm{T}$ cells (13), is significantly higher in synovial fluid $(70.1 \%)$ than in peripheral blood of patients $(16.7 \%)$ and controls (19.9\%). This is in accordance with reports on adult RA patients (14). No differences in synovial fluid and peripheral blood lymphocyte subsets were observed between patients of group A and group B. However, the fraction of $\mathrm{CD} 4^{+} \mathrm{CD} 29^{+}$
Table III. In Vitro Proliferative Response of Synovial Fluid Mononuclear Cells to Various Antigens*

\begin{tabular}{lcc}
\hline & Group A & Group B \\
\hline Purified protein derivative & 5.9 & 2.2 \\
MT & $49.1^{\ddagger}$ & 6.5 \\
AP & 2.6 & 1.5 \\
Mycobacterial HSP60 & 4.9 & 0.7 \\
183-188 & 3.3 & 1.1 \\
& $3.6^{\ddagger}$ & 0.7 \\
Human HSP60 & 1.1 & 0.9 \\
\hline
\end{tabular}

* Geometric mean expressed as stimulation index. Groups A and B are defined by a positive and negative $\mathrm{T}$ lymphocyte proliferative response to human HSP60, respectively (i.e, stimulation index $>$ or $<3$ ). $A P$, the acetone precipitable fraction of MT. ${ }^{\ddagger} P<0.05$, statistical significance between groups A and B is indicated.

cells in peripheral blood of group B was significantly higher than in group A $(36.1[n=4]$ vs $10.2 \%[n=9] ; P<0.05)$. Also in synovial fluid $\mathrm{CD} 4^{+} \mathrm{CD} 29^{+}$cells were higher in group $\mathrm{B}$ than in group $\mathrm{A}(93.1[n=2]$ vs $56.7 \%[n=4]$; no significant difference).

Proliferative responses of synovial fluid and peripheral blood mononuclear cells. Synovial fluid MNC of patients in group A showed significantly higher responses to MT and mycobacterial HSP60 than synovial fluid MNC of patients in group $B$ (Table III). For PBMC these responses were not significantly different between groups A, B, and the non-JCA controls (data not shown). For synovial fluid MNC a significant correlation was observed between the anti-human HSP60 responses and the response to MT $(r=0.900 ; P=0.002)$ and to mycobacterial HSP60 ( $r=0.842 ; P=0.004)$. When the correlation was analyzed for synovial fluid MNC of patients of group A, we found only a significant correlation between the response to human HSP60 and mycobacterial HSP60 ( $r=0.821 ; P$ $=0.028$ ). For PBMC a correlation was found between the response to human HSP60 and to MT ( $r=0.726 ; P=0.009)$. The in vitro response of synovial fluid MNC to the antigens tetanus toxoid and diphtheria toxoid was higher in patients of group A than in those of group B (data not shown). However, the difference was not statistically significant. Moreover, no correlation existed with lymphocyte reactivity to any of the HSP-related antigens.

Immunohistochemistry. Data on expression of HSP60 or related molecules in synovial membranes are presented in Table IV and Fig. 2. In the group of JCA patients (groups A and B together) and non-JCA controls, a cytoplasmic staining pattern was observed for the antibodies F-8, N-27, LK-1, and LK-2. The staining patterns of the various antibodies to HSP were not essentially different, but differences were observed in the intensity of labeling. On macrophages a higher expression of HLA-DR was found in JCA patients as compared with nonJCA controls (Fig. 2). When staining of the synovial lining layer, connective tissue, macrophages, and endothelium of blood vessels were scored together, significant differences in intensity were noted between samples of groups A, B, and the non-JCA controls (Table IV). Lowest intensity was found in the group of non-JCA control specimens. In addition, the score of staining of the synovial lining layer, connective tissue, macro- 
Table IV. Immunohistochemistry: Mean Sum of Score of Staining the Synovial Lining Layer, Endothelium of Blood Vessels, Connective Tissue, and Macrophages in Synovial Membranes

\begin{tabular}{llcc}
\hline & Group A & Group B & Non-JCA controls \\
\hline F-8 & $4.8^{*}$ & $6.8^{*}$ & 0.9 \\
ML-30 & $6.3^{*}$ & $6.0^{*}$ & 1.7 \\
N-27 & $4.0^{*}$ & $3.0^{*}$ & 1.3 \\
HLA-DR & 7.3 & 7.5 & 5.0 \\
LK1 & $5.3^{*}$ & 3.8 & 2.3 \\
LK2 & $5.5^{*}$ & 3.3 & 2.5 \\
\end{tabular}

$* P<0.05$, in statistical analysis of differences between groups $\mathrm{A}$ and $B$ and non-JCA controls. Groups A and B are defined by a positive and negative T lymphocyte proliferative response to human HSP60, respectively (i.e., stimulation index $>$ or $<3$ ).

phages, and endothelium of blood vessels was analyzed separately for the different antibodies (Fig. 2). A significant higher intensity of staining of the lining layer was found for F-8 (groups A and B versus controls, respectively; both $P<0.05$ ), ML-30 (group A versus controls; $P<0.001$ ), and for LK-2 (group A versus B and group A versus controls, respectively; both $P<0.05$ ). The intensity of staining by F-8 of the endothelium of the blood vessels was also significant higher (group A
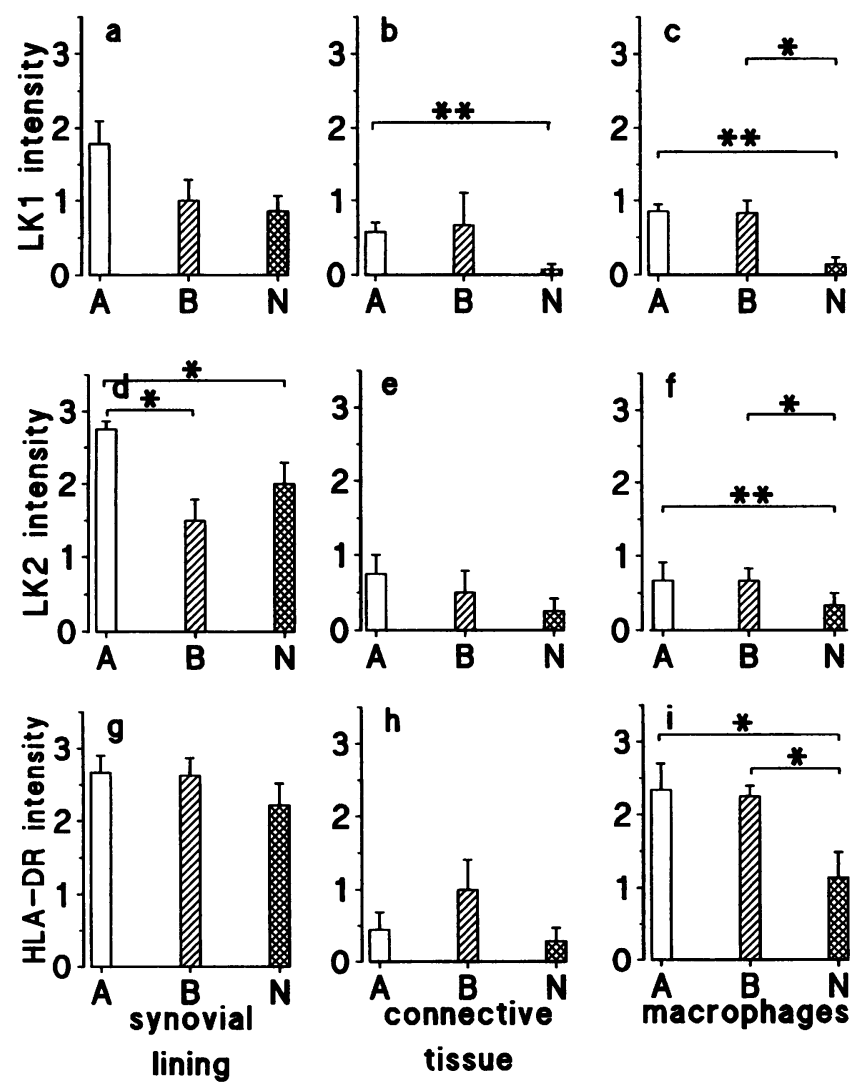

Figure 2. Analysis of intensity of staining in immunohistochemistry of synovial tissue sections with LK1 $(a-c)$, LK2 $(d-f)$, and anti-HLADR $(g-i)$. Groups A and B are defined by a positive and negative T lymphocyte proliferative response to human HSP60 (i.e., stimulation index $>$ or $<3$ ). Data are expressed as mean values +1 SEM.
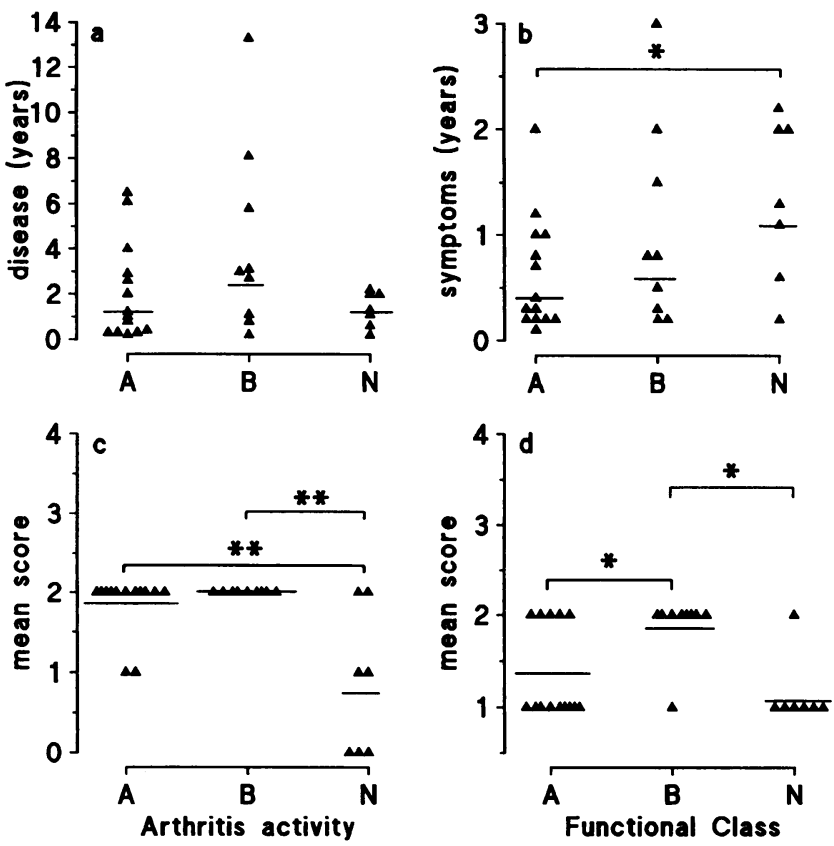

Figure 3. Mean duration of disease, arthritis, mean score of arthritis activity, and functional class of individual patients of groups A and B and non-JCA controls. Geometric mean values are indicated by drawn lines.

and B versus controls, respectively; both $P<0.05$ ). For the connective tissue, a significant higher intensity of staining was found for ML-30 (group A and B versus controls, respectively; both $P<0.05$ ), N-27 (group A versus controls; $P<0.05$ ), and LK-1 (group A versus controls; $P<0.05$ ). Macrophages showed significant differences for F-8 (group A and B versus controls, respectively; $P<0.001$ and 0.05 , respectively), ML30 (group A and B versus controls, respectively; both $P<0.05$ ), and HLA-DR (group A and B versus controls, respectively; both $P<0.05$; Fig. 2 and data not shown).

Analysis of clinical characteristics of the disease. The duration of the disease and of the current arthritis and the severity of the arthritis and functional class score were compared between all patients from groups A and B and the control group (Fig. 3). The duration of the disease was not significantly different between JCA patients of groups A and B and the non-JCA controls. The duration of the arthritis was significantly shorter for group A than the non-JCA controls $(P<0.05)$. The score of arthritis activity was significantly higher in group A (mean score 1.8; range 1-2) and group B (mean score 2 for all patients) than in the non-JCA controls (score 1 for all non-JCA controls; both $P<0.05)$. The score of the functional class of the patients of group A (mean score 1.4; range 1-2) differed significantly from group B (mean score 1.8; range $1-2 ; P<0.05$ ). The score of the functional class of group $B$ was significantly different from the non-JCA controls (median score 1; range 1-2; $P<0.05)$.

\section{Discussion}

Heat shock proteins have received ample attention as possible target antigens of the immune response in both infectious and autoimmune diseases $(15-19)$. The proteins are highly evolu- 
tionarily conserved and they behave as dominant immunogens. In the experimental model of AA, mycobacterial HSP60 has been identified as the key antigen. The crucial epitope was located at amino acid positions 180 to 188 (3). The amino acid sequence of this epitope shows sequence homology with rat proteoglycan link protein, which supports earlier suggestions that rat proteoglycan is a target antigen in AA (20). However, the alternative possibility of endogenous HSP as a potential target antigen in arthritis in rats remains to be substantiated. Recently, we could document $\mathrm{T}$ lymphocyte reactivity to human HSP60 in patients with JCA (7) and the same phenomenon was found in reactive arthritis (21). Since bacterial and human HSP60 show a $60 \%$ sequence identity at the amino acid level (22), this has led to the hypothesis that a response originally triggered by bacterial HSP might induce $\mathrm{T}$ lymphocytes which recognize epitopes shared by bacterial and self $\operatorname{HSP}(15,23)$. Alternatively, it is possible that the antibacterial HSP reactivity is secondary to the reactivity against endogenous HSPs, overexpressed in the joint during inflammation.

Recently it was shown that $\mathrm{T}$ cell clones from synovial fluid of HLA-B $27^{+}$JCA patients that were raised against mycobacterial HSP65 also could be induced to proliferate to GroEL or human HSP60 (24), and it was suggested that the response to both mycobacterial HSP65 and human HSP60 could be caused by contaminating GroEL in those preparations. In our studies, we have used HPLC-purified recombinant human HSP60. Although during the production procedure recombinant human HSP60 is insoluble while GroEL is a soluble protein, and although there was no reactivity with GroEL recognizing mAbs, we cannot rule out that the recombinant product is contaminated with trace amounts of GroEL, the $E$. coli equivalent of human HSP60. In vitro culture of JCA T cells with GroEL in doses up to $10 \mu \mathrm{g} / \mathrm{ml}$, however, induced only modest responses in 3 out of 11 patients studied for that purpose. Furthermore, it should be noted that in vitro culture with the control preparation (HPLC-purified material from mock-transfected bacteria [7]) in no case induced $\mathrm{T}$ cell proliferation above the medium control. This indicates that the T cell proliferation to human HSP60 as observed in primary cultures of peripheral blood lymphocytes of HLA-B27- JCA patients cannot be attributed to contaminating GroEL.

To investigate the significance of a positive $\mathrm{T}$ lymphocyte proliferative response to human HSP60, we made a comparison between JCA patients with a positive response (group A) and patients with a negative response (group B) with regard to lymphocyte subset distribution, expression of HSP in synovial membranes, and clinical characteristics. As far as the lymphocyte phenotyping is concerned, we observed a significant increase in $\mathrm{CD}^{+} \mathrm{DR}^{+}$and $\mathrm{CD}^{+} \mathrm{DR}^{+} \mathrm{T}$ lymphocytes in the synovial fluid of both group $A$ and $B$. This underscores the role of T lymphocytes in the inflammatory process in the joint. A number of previous studies have characterized lymphocyte subsets in the synovial fluid and peripheral blood of patients with JCA by analyzing MNC for cell surface markers and several activation markers (for review see reference 25). Generally, synovial fluid lymphocytes showed a decrease in $\mathrm{CD}^{+} \mathrm{T}$ cells, an increase in $\mathrm{CD}^{+} \mathrm{T}$ cells, and an increase in $\mathrm{T}$ cells with varying activation markers. Data in JCA patients are similar to those of patients with the adult form of RA $(14,26)$. We documented an increase of $\mathrm{CD} 4^{+} \mathrm{CD} 29^{+}$memory T cells (13) in the synovial fluid and peripheral blood of patients with JCA (Table II). The highest percentage was found in group B, i.e., in those patients with a tendency for longer duration of disease and symptoms (Fig. 3). These results suggest an ongoing lymphocyte-mediated process in patients of group B. Since these patients are by definition nonreactive to human HSP60, the results of T cell phenotyping may suggest more profound defective immunoregulation than in patients of group A. However, whether the results of phenotyping are directly related to human HSP60 reactivity remains to be clarified. In adult RA patients it is shown that the percentage of $\mathrm{CD} 4{ }^{+} \mathrm{CD} 29^{+}$is higher in synovial fluid than in peripheral blood (14). The finding of the highest number of $\mathrm{CD} 4{ }^{+} \mathrm{CD} 29^{+}$cells in group $\mathrm{B}$ is interesting since these patients most resemble the seronegative adult RA patients in many aspects.

The pattern of expression in the synovial membranes of human HSP60 as detected by the monoclonal antibody LK-I paralleled expression of HSP-related molecules as demonstrated by the crossreactive antibodies LK-2, F-8, and ML-30 $(7,8)$. The results showed that the JCA patients of both groups showed a higher intensity of labeling of the antibodies than the controls (Table IV). The pattern of staining and the localization (Fig. 2) were similar to our earlier findings in RA patients (8), where only crossreactive antibodies were used. In one patient (Table I, patient 4), we observed immunohistochemical expression of human HSP60 or crossreactive molecules in a very early phase of the disease while the proliferative response to human HSP60 was not yet positive. 2 mo later while the disease was still active, a proliferative response to human HSP60 developed. In three other patients with JCA (not included in this study), we observed expression of HSP60 and crossreactive molecules in the synovial membranes after only $6 \mathrm{wk}$ of arthritis, preceding the development of a positive response to human HSP60 in PBMC.

All but four of the patients of group A had an oligoarticular onset of JCA. The mean duration of the disease and the mean duration of the current arthritis were shorter in group A than in group B. In addition, the patients of group A had a less severe course of the disease, which is reflected in a significantly lower functional class as compared with the patients of group B (Fig. 3 ). Group B consists of the majority of patients with either a polyarticular onset of JCA or HLA-B27-positive patients with an oligoarticular onset of JCA. These are exactly the groups with a nonremitting course of disease. Group B comprised two HLA-B27-negative patients with oligoarticular onset (patients 16 and 20), who both were tested early in the course of the arthritis. It is conceivable that if they were tested in a later stage they could have belonged to group A. It is known that patients with an oligoarticular JCA generally have a short and benign course of their disease. Follow-up studies of four of the patients of group A show that the response to human HSP60 disappears when the arthritis came in remission (Prakken, A. B. J., W. van Eden, G. T. Rijkers, W. Kuis, E. A. Toebes, E. R. de GraeffMeeder, R. van der Zee, and B. J. M. Zegers, manuscript in preparation).

Taken together our results show that in vitro $\mathrm{T}$ cell response to human HSP60 predominantly, though not exclusively, occurs in JCA patients of the HLA-B27-negative oligoarticular subgroup with an active arthritis. Since patients from this subgroup of JCA usually show a short term of disease and favorable outcome it is tempting to hypothesize that $\mathrm{T}$ cell reactivity to human HSP60 in these patients is associated with immunoregulatory control rather than with progression of disease. Our results also show that $T$ cell reactivity to human HSP60 is not 
strictly confined to the subgroup of patients with an oligoarticular onset but may occur in polyarticular JCA patients as well (this study and our unpublished results). The selection of HSP epitopes for T lymphocyte activation, that may determine progression and outcome of the disease, may be different for patients with either the oligoarticular onset type or the polyarticular type of disease. The finding that the various JCA subtypes show different HLA associations supports this concept (27). In our group of patients, the frequency of HLA susceptibility alleles (e.g., 41\% HLA-DPB1*0201) corresponded with known HLA associations in JCA (28). There was, however, no relation between any particular HLA haplotype or allele and the in vitro anti-human HSP60 T cell response (data not shown). As such, this is not surprising because we have used the full-length recombinant HSP60 molecule. Future studies should be directed to establish the epitopes of human HSP60 selected by T cells in the various subgroups of JCA patients.

\section{Acknowledgments}

We thank Drs. M. Tilanus (Molecular Diagnostic DNA Laboratory, Academic Hospital, Utrecht, The Netherlands), F. J. Claas (Department of Immunohaematology, Academic Hospital, Leyden, The Netherlands) for HLA genotyping, and A. Bloemendal (Institute of Infectious Diseases and Immunology, Faculty of Veterinary Medicine, Utrecht, The Netherlands) for human HSP60 ELISA.

\section{References}

1. Wood, P. H. N. 1978. Special meeting on nomenclature and classification of arthritis in children. In The Care of Rheumatic Children. E. Munthe, editor. Eular Publishers, Basel, Switzerland. 47-50.

2. van Eden, W. 1991. Heat-shock proteins and the immune system. Immunol. Rev. 121:5-28.

3. van Eden, W., J. E. R. Thole, R. van der Zee, A. Noorzij, J. D. A. Embden, E. J. Hensen, and I. R. Cohen. 1988. Cloning of the mycobacterial epitope recognized by $\mathrm{T}$ lymphocytes in adjuvant arthritis. Nature (Lond.). 331:171-173.

4. Thompson, S. J., G. A. W. Rook, R. J. Brealey, R. van der Zee, and C. J. Elson. 1990. Autoimmune reactions to heat-shock proteins in pristane-induced arthritis. Eur. J. Immunol. 20:2479-2484.

5. van den Broek, M. F., E. J. M. Hogervorst, M. C. J. van Bruggen, W. van Eden, R. van der Zee, and W. B. van der Berg. 1989. Protection against streptococcal cell wall-induced arthritis by pretreatment with the $65-\mathrm{kD}$ mycobacterial heat shock protein. J. Exp. Med. 170:449-466.

6. Ito, J., J. Krco, D. Yu, H. S. Luthra, and C. S. David. 1991. Preadministration of a $65 \mathrm{kDa}$ heat shock protein GroEL inhibits collagen induced arthritis in mice. J. Cell. Biochem. 15A:284.(Abstr.)

7. de Graeff-Meeder, E. R., R. van der Zee, G. T. Rijkers, H.-J. Schuurman, W. Kuis, J. W. J. Bijlsma, B. J. M. Zegers, and W. van Eden. 1991. Recognition of human $60 \mathrm{kD}$ heat shock protein by mononuclear cells from patients with juvenile chronic arhthritis. Lancet. 337:1368-1372.

8. de Graeff-Meeder, E. R., M. Voorhorst, W. van Eden, H.-J. Schuurman, J. Huber, D. Barkley, R. N. Maini, W. Kuis, G. T. Rijkers, and B. J. M. Zegers.
1990. Antibodies to the mycobacterial $65-\mathrm{kD}$ heat shock protein are reactive with synovial tissue of adjuvant arthritic rats and patients with rheumatoid arthritis and osteoarthritis. Am. J. Pathol. 137:1013-1017.

9. Steinbrocker, O., C. H. Traeger, and R. C. Batterman. 1949. Therapeutic criteria in rheumatoid arthritis. JAMA (J. Am. Med. Assoc.). 140:659-662.

10. Holoshitz, J., A. Klajman, I. Drucker, Z. Lapidot, A. Yaretzky, A. Frenkel, W. van Eden, and I. R. Cohen. 1986. T lymphocytes of rheumatoid arthritis patients show augmented reactivity with a fraction of mycobacteria cross-reactive with cartilage. Lancet. ii:305-309.

11. Steward, J. M., and J. D. Young. 1984. Solid phase peptide synthesis. Pierce Chemical Co., Rockford, IL. (Abstr.)

12. Boog, C. J. P., E. R. de Graeff-Meeder, M. A. Lucassen, R. van der Zee, M. M. Voorhorst-Ogink, P. J. S. van Kooten, H. J. Geuze, and W. van Eden. 1992. Two monoclonal antibodies generated against human hsp60 show reactivity with synovial membranes of patients with juvenile chronic arthritis. J. Exp. Med. 175:1805-1810.

13. Sanders, E. M., M. W. Makgoba, and S. Shaw. 1988. Human naive and memory T cells: reinterpretation of helper-inducer and suppressor-inducer subsets. Immunol. Today. 9:195-199.

14. Cush, J. J., and P. E. Lipsky. 1991. Cellular basis for rheumatoid inflammation. Clinical Orthopaedics and Related Research. 265:9-22.

15. Lamb, J. R., V. Bal, P. Mendez-Samperio, A. Mehlert, A. So, J. Rothbard, S. Jindal, R. A. Young, and D. B. Young. 1989. Stress proteins may provide a link between the immune response to infection and autoimmunity. Int. Immunol. 1:191-196.

16. Young, R. A., and T. J. Elliott. 1989. Stress proteins, infection and immune surveillance. Cell. 59:5-8.

17. Young, R. A. 1990. Stress proteins and immunology. Annu. Rev. Immunol. 8:401-420.

18. Kaufmann, S. H. E. 1990. Heat shock proteins and the immune response. Immunol. Today. ii:129-136.

19. Gaston, J. S. H. 1991. Heat shock proteins and autoimmunity. Semin. Immunol. 3:35-42.

20. van Vollenhoven, R. F., A. Soriano, P. E. McCarthy, R. L. Schwartz, F. C. Garbrecht, G. J. Thorbecke, and G. W. Siskind. 1988. The role of immunity to cartilage proteoglycans in adjuvant arthritis. Intravenous injection of bovine proteoglycan enhances adjuvant arthritis. J. Immunol. 141:1168-1173.

21. Hermann, E., A. W. Lohse, R. van der Zee, W. van Eden, W. J. Mayet, P. Probst, T. Poralla, K.-H. Meyer zum Buschenfelde, and B. Fleischer. 1991. Synovial fluid-derived Yersinia-reactive T cells responding to human $65-\mathrm{kDa}$ heat-shock protein and heat-stressed antigen-presenting cells. Eur. J. Immunol. 21:2139-2143.

22. Jindal, S., A. K. Dudani, C. B. Harley, B. Singh, and R. S. Gupta. 1989. Primary structure of a human mitochondrial protein homologous to bacterial and plant chaperonins and to $65 \mathrm{kD}$ mycobacterial antigen. Mol. Cell. Biol. 9:22792283.

23. Winfield, J. B. 1989. Stress proteins, arthritis and autoimmunity. Arthritis Rheum. 32:1497-1504.

24. Life, P., A. Hassell, K. Williams, S. Young, P. Bacon, T. Southwood, and J. S. H. Gaston. 1993. Responses to gram negative enteric bacterial antigens by synovial $\mathrm{T}$ cells from patients with juvenile chronic arthritis: recognition of heat shock protein HSP60. J. Rheumatol. 20:1388-1396.

25. Lang, B. A., and A. Shore. 1990. A review of current concepts on the pathogenesis of juvenile rheumatoid arthritis. J. Rheumatol. 17:1-15.

26. Kluin-Nelemans, M. C., J. A. Linden, F. H. J. Gmelig Meyling, and H.-J. Schuurman. 1984. HLA-DR positive T lymphocytes in blood and synovial fluid in rheumatoid arthritis. J. Rheumatol. 11:272-276.

27. Maksymowych, W. P., and D. N. Glass. 1988. Population genetics and molecular biology of the childhood chronic arthropathies. Bailliere's. Clin. Rheumatol. 2:649-671.

28. Nepom, B. S., and D. N. Glass. 1992. Juvenile rheumatoid arthritis and HLA: report of the Park City II Workshop. J. Rheumatol. 19(Suppl. 33):70-74. 